\title{
Experimental and numerical characterization of an oyster farm impact on the flow
}

\author{
Benoît Gaurier $^{\mathbf{a}, \mathbf{b}, *}$, Grégory Germain ${ }^{\mathbf{a}, \mathbf{b}}$, Youen Kervella ${ }^{\mathbf{c}, \mathbf{d}}$, Julia Davourie $^{\mathbf{a}}$, Florence Cayocca ${ }^{\mathbf{c}}$, \\ Patrick Lesueur ${ }^{\mathrm{d}}$
}

\author{
a Ifremer, Hydrodynamic \& Metocean Service F-62200 Boulogne-sur-Mer, France \\ ${ }^{\mathrm{b}}$ Univ. Lille Nord de France, F-59000 Lille, France \\ c Ifremer, PHYSED Lab, F-29280 Plouzané, France \\ d Univ. Caen, M2C Lab - CNRS/INSU UMR 6143, F-14000 Caen, France \\ *: Corresponding author : Benoît Gaurier, Tel.: +33 321995633 ; fax: +33 321995671. \\ email address : benoit.gaurier@ifremer.fr
}

\begin{abstract}
:
Shellfish farming, particularly oyster farms, suffers from strong siltation phenomena which are harmful to the production of shellfish. The lack of knowledge about the impact of an oyster farm on the wave propagation and on the flow remains a significant difficulty for the comprehension of sediment transport processes in coastal zones. These effects are one of the possible sources of sedimentation. The study presented here focuses on describing finely hydrodynamical phenomena (velocity fields, turbulence parameters) around oyster tables. The analysis is based on experimental trials carried out in a flume tank on reduced models of oyster tables. Experiments highlight the flow perturbations in the near field and constitute a database for validation of numerical models developed at the same time. The model based on Navier-Stokes equations offers the possibility to study the impact of more realistic table lengths on the flow and to simulate the perturbation produced by a group of oyster tables. Both experimental and numerical results are presented in this paper.
\end{abstract}

Keywords : Sediment dynamics; Oyster table; LDV measurement; Computational fluid dynamics; Porosity; Boundary layer 


\section{Introduction}

Since long-term sedimentation became a real problem for shellfish exploitation in France [1]. An increase in the bed level by sediment deposits is usually observed around the structures. This effect could be inherent in the farming technique with elevated tables which could induce a decrease in velocity and a deviation of the tidal flow, a local agitation weakening and a flow canalization [2]. These phenomena are directly or indirectly responsible for mortality events [3]. In order to overcome this phenomenon it is essential to understand the effects induced by oyster or mussel farms on sediment transport. Modifications of local hydrodynamics by shellfish farming structures have to be added to natural progressive infill processes to explain the observed sedimentation rate in inter-tidal areas of a bay.

In previous studies $[4,5,6]$, numerical simulations were carried out in order to estimate the effects of mussel farms on the flow. SeaMER [6] used a numerical model of $10 \mathrm{~cm}$ mesh to compute hydrodynamic effects of $2.40 \mathrm{~m}$ mussel posts of $0.40 \mathrm{~m}$ in diameter. The results have shown a decrease of the flow speed upstream a single post as well as in the wake, while the velocity increased on both sides of the post. But a row of posts had no influence on the overall current velocity, local accelerations and decelerations of the flow cancelling each other. This study was never validated by experiments or in-situ measurements.

Cayocca et al. [5] introduced the effects of mussel farms on flow circulation and sediment dynamics into a wide-extension numerical model by increasing the hydraulic roughness used for velocity computations at the location of mussels structures. This study opens a way of modeling mussel or oyster structures implantation at the scale of a bay but needs to be validated and particularly, the local hydrodynamic processes need to be more accurately described. Stevens et al. [7] reviewed issues relating to the design and mechanics of shellfish long-line structures in relation to the offshore marine environment. They identified a number of future applied research topics like mooring design, vertical drag coefficients or wave-current interaction.

As for the oyster structures, a decrease of the velocity and a deviation of the tidal flow was locally observed in the field [2]. The impact of these structures on the wave pattern and on the wave orbital velocities was experimentally estimated in [8] with a few restrictions: tables were simply modeled by horizontal solid plates, only studied under wave effects at normal inci-

dence. 
A recent experimental study in a flume tank [9] highlights an asymmetric development of the boundary layers and an important decrease in flow velocity around a single table of finite length, which suggests the existence of preferential areas for silting-up and suspended matter fragmentation under the table. The considered oyster table is a metallic wire structure on which porous bags containing small oysters are laid in order to grow (figure 1).
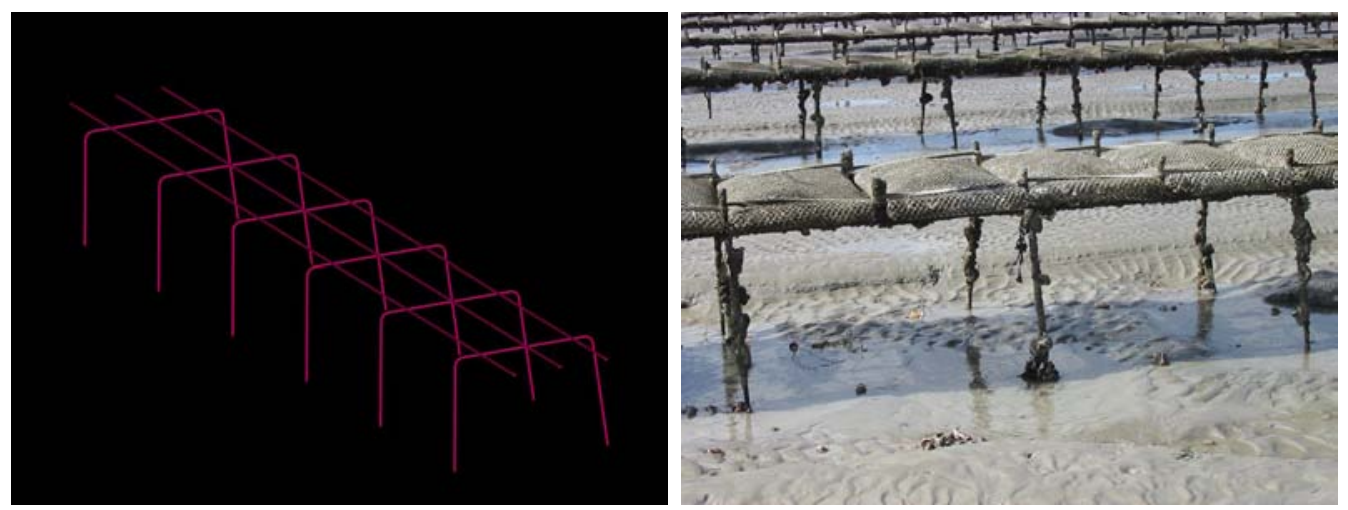

Figure 1: Sketch of an $3.60 \mathrm{~m}$ long oyster table without the oyster bags on the left and real table in the field with oyster bags on the right

The oyster table used in these tests is modeled at $1 / 2$ scale, with a finite length of $7.20 \mathrm{~m}$ whereas the length of the table model should be $50 \mathrm{~m}$ for the modeling of a real table of $100 \mathrm{~m}$. During these experiments, Kervella et al. [9] compared the flow perturbation around a $3.60 \mathrm{~m}$ and $7.20 \mathrm{~m}$ long tables aligned with the flow. It appears that the boundary layers above and under a $3.60 \mathrm{~m}$ long table are not both fully developed, while the boundary layer above a $7.20 \mathrm{~m}$ long table stops to grow after around $6.50 \mathrm{~m}$ while the velocity under the table continues to decrease.

This previous study shows that the length is an essential parameter in order to correctly reproduce the interaction between the flow and the structure. But real lengths, because of their large dimensions, are impossible to obtain in a flume tank. So, numerical simulations are conducted in order to reach these table lengths.

Before introducing the numerical work achieved during this study, we present an extension of the previous experimental trials for new configurations used for the validation of the numerical model. After the description of the model based on the Navier-Stokes equations using the Ansys Fluent ${ }^{\mathrm{TM}}$ 
software, we present comparisons of experimental and numerical results. The quality of the results obtained with reduced table length allows to extend to real table size. This work is presented in the last section.

\section{Experimental study}

\subsection{Setup}

Experiments have been carried out in 2008 and 2009 in the Ifremer (French Research Institute for Exploration and Exploitation of the Sea) waves and currents flume tank in Boulogne-sur-Mer, France (figure 2). The flume tank is $18 \mathrm{~m}$ long by $4 \mathrm{~m}$ wide and $2 \mathrm{~m}$ deep with a side observation window of $8 \mathrm{~m} \times 2 \mathrm{~m}$. The flow turbulence can be adjusted between $5 \%$ and $30 \%$ and the flow velocity range is: 0.1 to $2.2 \mathrm{~m} / \mathrm{s}$.
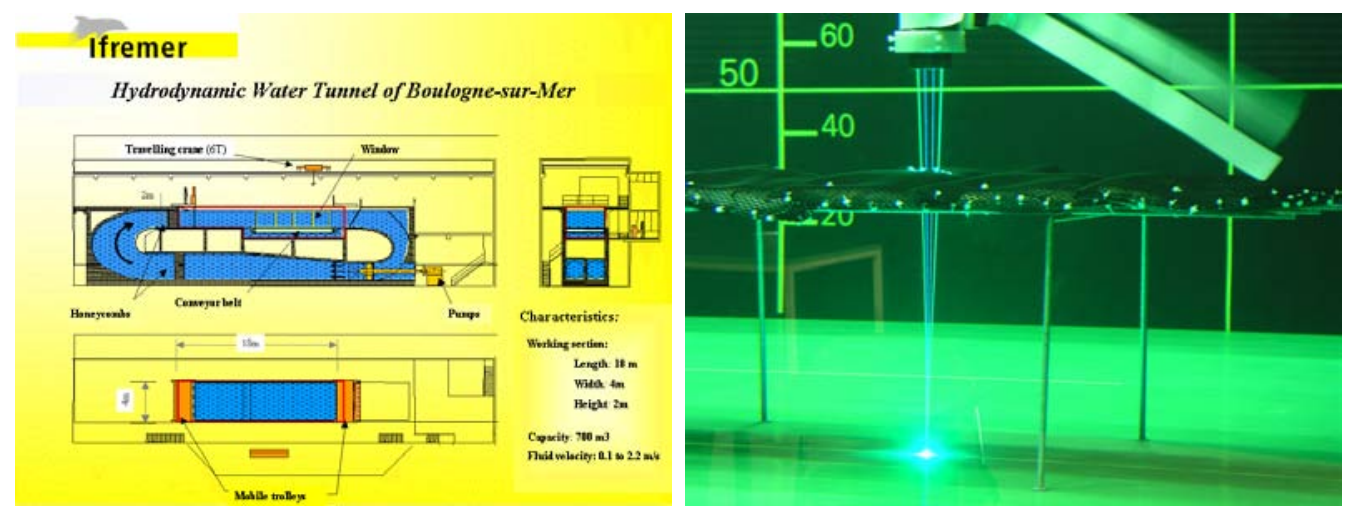

Figure 2: Presentation of the Ifremer flume tank on the left and of the oyster table model during laser measurement on the right

In the field, an oyster table is typically $100 \mathrm{~m}$ long by $1 \mathrm{~m}$ wide and $0.7 \mathrm{~m}$ high. A good understanding of the current-table interactions drive the choice of a $1 / 2$ scaled model according to Froude similarity. Representing the whole table lengthwise would require a much greater scale. However, previous trials [9] show that a length of $7.20 \mathrm{~m}$ gives a good knowledge of the flow interaction with the structure: the length is sufficient enough for the upper boundary layer establishment. These dimensions were also chosen so as to allow multi-orientations in the tank, with a low blockage ratio. The oyster table model is made of $8 \mathrm{~mm}$ diameter galvanized iron rod. The oyster bags are manufactured with the same plastic nets as used in the field, but with $7 \mathrm{~mm}$ meshes (half as large as in the field), while the size ratio between 
reality and experiments is preserved. The bags are filled with pebbles used to simulate oysters. Cylindrical holes are cut out in the middle of a few bags in order to allow laser measurements under the table (figure 2).

The modeled table is therefore $7.20 \mathrm{~m}$ long by $0.50 \mathrm{~m}$ wide and $0.35 \mathrm{~m}$ high. The water depth used for these tests is $2 \mathrm{~m}$, the flow velocity is set to $0.5 \mathrm{~m} / \mathrm{s}$ and the flow turbulence rate is close to $5 \%$. For a precise localization of the velocity profiles that will be described in the experimental or numerical parts, a global frame of reference $(O, x, y, z)$ is chosen. The origin is set at the middle of the upstream table side, just under the first bag. $O x$ is the in-line axis and also the main flow direction axis, $O y$ is the vertical axis and $O z$ is the transverse axis (figure 3 ).

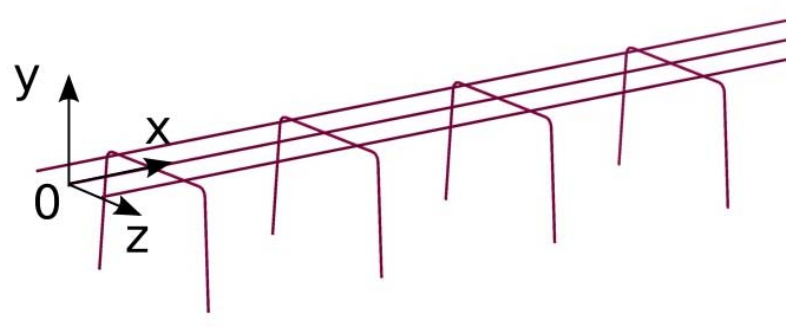

Figure 3: Presentation of the global frame and reference axis $(O, x, y, z)$

Most of the time, tables in the field are aligned with the main flow direction. However fairly random orientations may be encountered, and tables are even sometimes perpendicular to the main flow direction. This "misalignment" can also come from the flow variations along the coast and during the reverse of the tidal flow. In order to have a good idea of oyster table effects on the flow pattern for various conditions, we consider three configurations:

- configuration A: the oyster table direction is parallel to the mean flow direction (figure 4(a)).

- configuration B: the angle between the oyster table direction and the mean flow direction equals $15^{\circ}$ (figure $4(\mathrm{~b})$ ).

- configuration C: two oyster tables of $3.6 \mathrm{~m}$ long are positioned perpendicular to the mean flow direction (figure 4(c)) and spaced by $2.5 \mathrm{~m}$. 


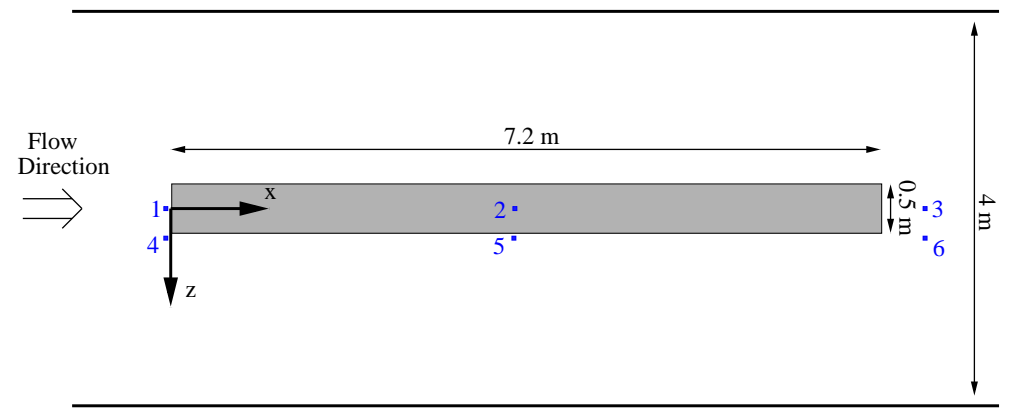

(a) Configuration $\mathrm{A}$

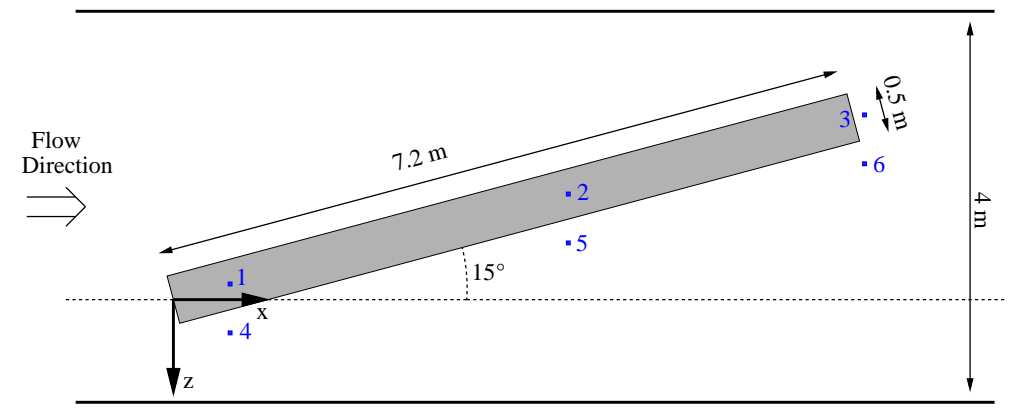

(b) Configuration B

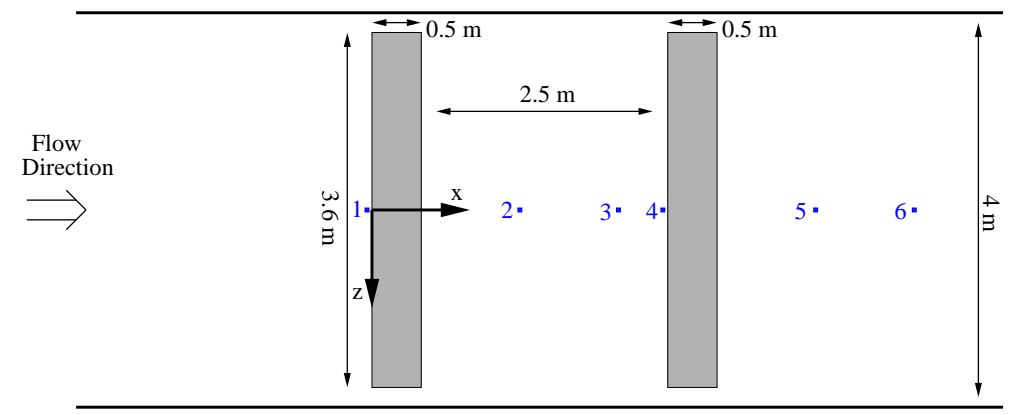

(c) Configuration $\mathrm{C}$

Figure 4: Presentation of configurations used in the tank from which flow measurements were made (top views). Blue points: locations of comparisons between experimental and numerical results in section 3.4

For each configuration, 6 points of reference are chosen for experimental and numerical comparisons made in section 3.4.

For each configuration, about 40 vertical and horizontal velocity measurements along profiles are performed upstream, along and downstream the table structure. A velocity profile is composed of more than 15 measure- 
ment points. These points are presented on the figure 5 for configuration A. The flow velocity is measured using a 2D Laser Doppler Velocimetry system (LDV), on the plane $\mathrm{Z}=0 \mathrm{~m}$ and $\mathrm{Z}=0.30 \mathrm{~m}$.

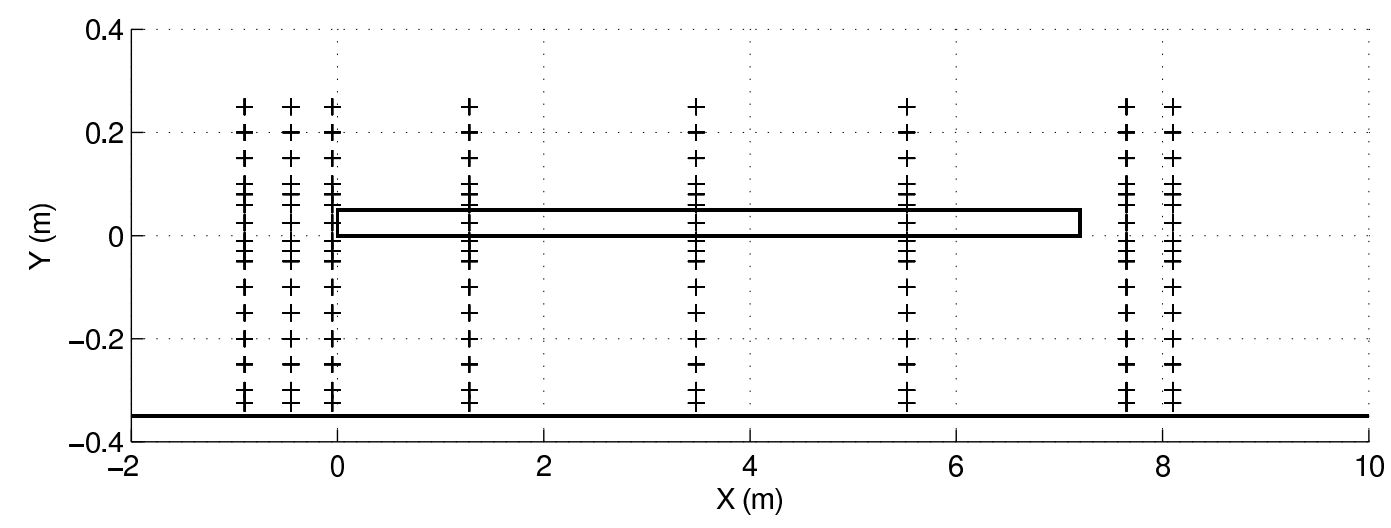

Figure 5: Experimental points of velocity measurements for configuration $\mathrm{A}$ in the plane $\mathrm{Z}=0 \mathrm{~m}$ (side view)

LDV measurements along the monitoring profiles are interpolated in order to generate $2 \mathrm{D}$ velocity maps in $x O y$ and $x O z$ plans. The extrapolation between two profiles was compared and validated from PIV results in a previous work [9]. In each measurement location, the velocity is acquired during $100 \mathrm{~s}$. For four different profiles, the time of acquisition is extended to $420 \mathrm{~s}$ in order to obtain the convergence of shear stress calculations [10].

Shear stresses are calculated using the Reynolds shear stress method, also defined as the covariance method:

$$
\tau=\rho \overline{u^{\prime} v^{\prime}}
$$

where $u^{\prime}$ and $v^{\prime}$ are the velocity fluctuations along the horizontal $O x$ and vertical $O y$ axis respectively and $\rho$ is the water density.

An other parameter studied in this paper is the Turbulence Kinetic Energy (TKE) quantified here by the mean of the turbulence normal stresses:

$$
k=\frac{1}{2}\left(\overline{u^{\prime 2}}+\overline{v^{\prime 2}}+\overline{w^{\prime 2}}\right)
$$

where $w^{\prime}$ is the velocity fluctuations along the transverse $O z$ axis which is not measured by the laser. Kervella et al. [9] show that the flow has the 
same way of skirting around the table along the $O y$ direction and along the $\mathrm{Oz}$ direction. So, the assumption is made that the fluctuating part of the vertical velocity component is equal to the fluctuating part of the transverse velocity component, i.e. $w^{\prime} \simeq v^{\prime}$.

\subsection{Experimental results}

Results of configuration A (figure 6, top) highlight important areas of velocity decrease, under and next to the table. In terms of sediment transport, it involves a decrease of the sediment transport rate and preferential deposition areas $[9,10]$.

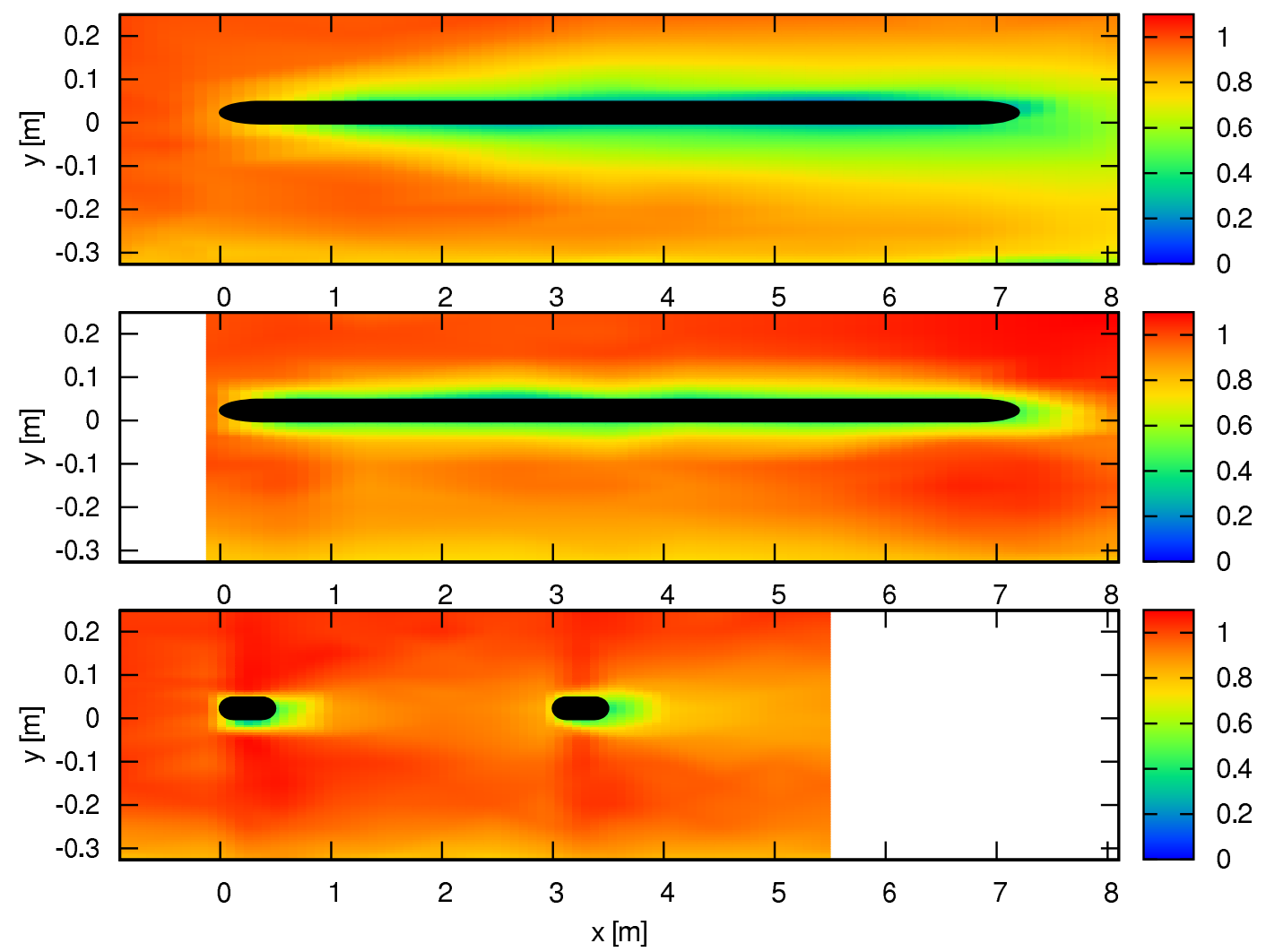

Figure 6: Normalized longitudinal velocities on the median vertical plane of the tables for configurations A (top), B (middle) and C (bottom)

In configuration $\mathrm{B}$ (figure 6, middle), modifications of the flow direction under the oyster table is observed close to the bottom by Kervella et al. 
[10], which actually confirms the in-situ measurements carried out in the Mont-Saint-Michel Bay [11].

Shear stresses measurements reveal that there is no consistent modification on the bottom in these two configurations, i.e. no direct impact on the bottom sediment but there is an increase of the total shear stress which leads to energy dissipation by turbulence. This energy dissipation involves an overall flow decrease, and in turn modifications of sediment transport patterns at a greater spatial scale.

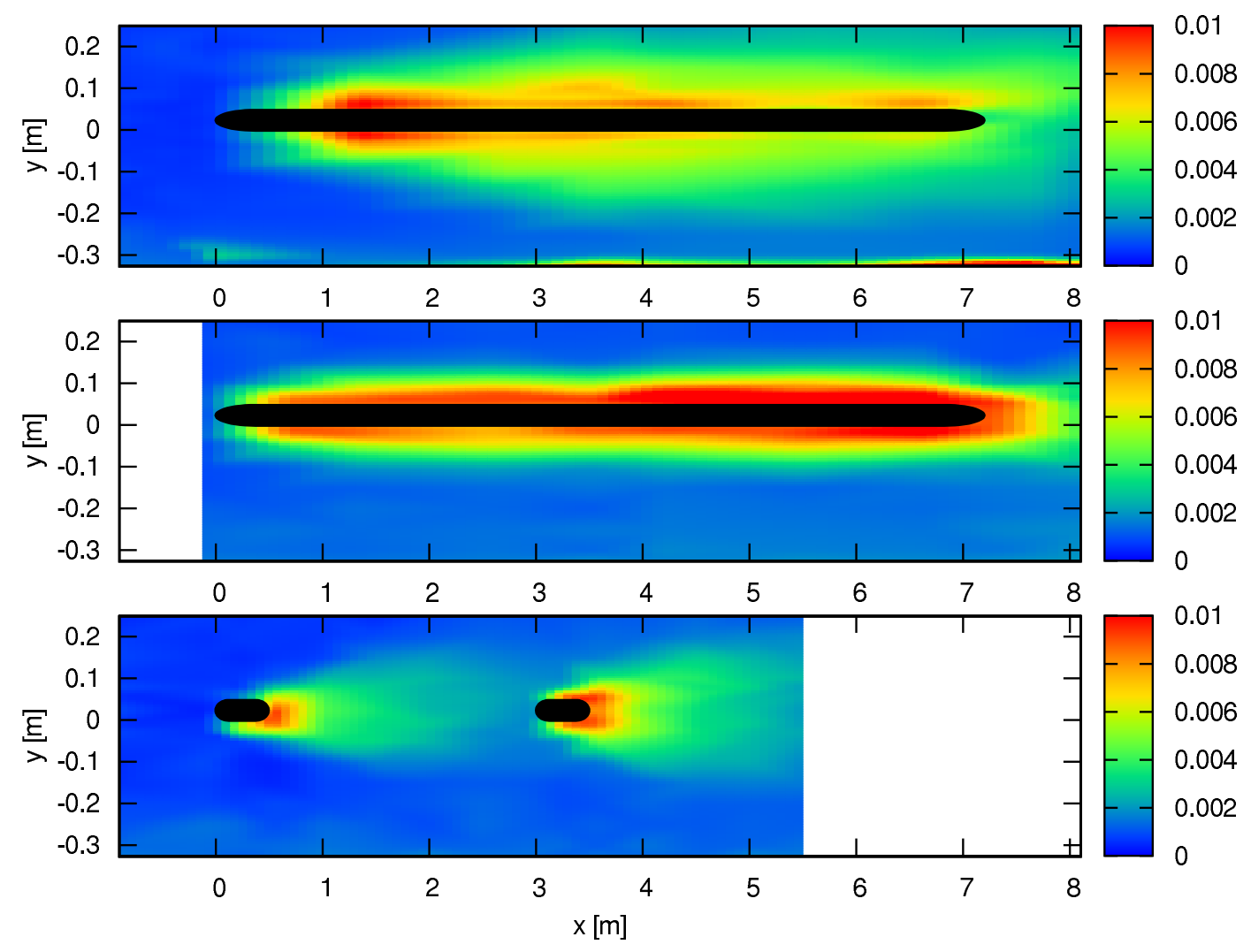

Figure 7: Turbulent Kinetic Energy $\left(\mathrm{m}^{2} / \mathrm{s}^{2}\right)$ on the median vertical plane of the tables for configurations A (top), B (middle) and C (bottom)

As for configuration C (figure 6, bottom), the development of tableinduced boundary layers is quite similar behind both tables, except for a slight masking effect between the two tables. This masking effect leads to a more important vertical extension of the velocity decrease area behind the 
second table. This area representing the wake of the tables, exhibits local decelerations up to $20 \%$ of the upstream velocity.

The bottom boundary layer seems to be slightly affected when the flow is passing through both tables. This local phenomenon might be due to the observed acceleration area (in red) located just under the tables, which is an area of interest since the oysters biodeposits can be directly advected from under the tables by this faster velocity.

The TKE distribution around the overall table is shown on figure 7 for configurations A, B and C. For each configuration, table-induced TKE does not propagate all the way to the tank bed. The table presence impacts a part of the water column and the inherent suspended particles processes, such as flocculation or fragmentation, but not directly the bottom processes, such as sediment erosion or deposition.

Figure 8 shows that there is no modification of the bottom shear stress after the first and the second table. However, the shear stress on the whole water column, which is computed as the sum of contributions at the bottom boundary, at the inferior side and superior side of the table [10], is multiplied by 25 just downstream the first table and by 35 when the flow is going through the second one. The same conclusions can be drawn about energy dissipation. The effect of the succession of tables is an increase of the total shear stress and hence of energy dissipation.

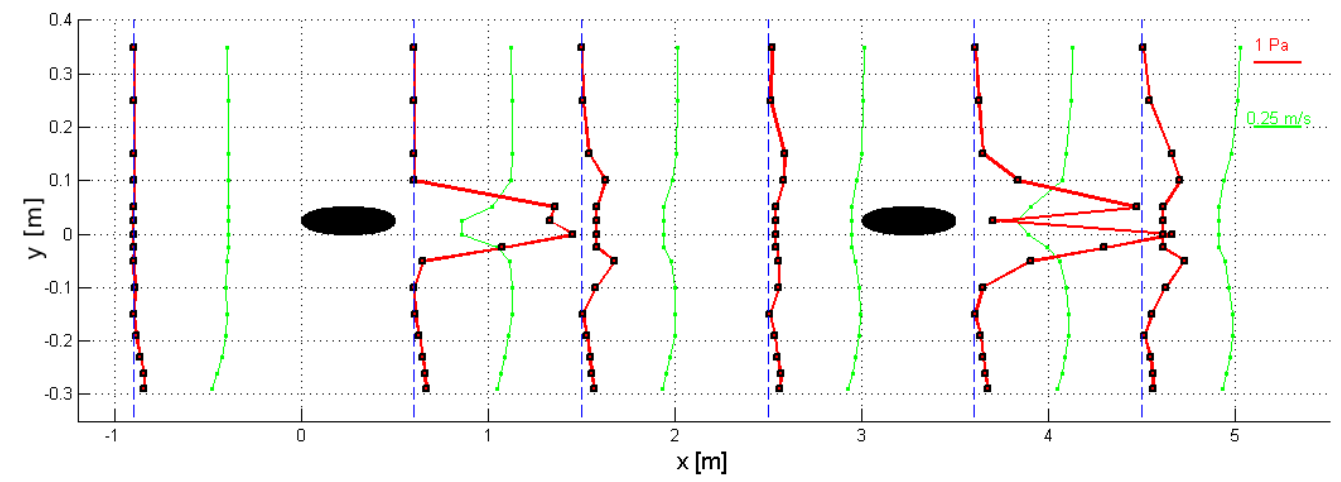

Figure 8: Reynolds shear stresses (red lines) and longitudinal velocities (green lines) on the median vertical plane across two $3.60 \mathrm{~m}$ tables, configuration $\mathrm{C}$

Moreover, a "break point" appears, just downstream the second table, 
which characterizes a large velocity decrease (an attenuation of 50\%) and a small value for the shear stress $(0.4 \mathrm{~Pa})$. Similar points are also noticed for configuration B by Kervella et al. [10] with very low shear stress values just downstream the table.

These experimental campaigns allowed a detailed investigation of the impact of an oyster table on the flow which is now quit well understood at this scale. Due to the restrictions made for the experimental modeling (reduction of the table length, limitation to one or two tables), it is difficult to extend these results to the configurations encountered in the field with high number of tables of several hundred of meters. In order to reach more realistic table lengths and to simulate the impact of a whole oyster farm on the flow, a numerical tool is therefore developed and calibrated with these experimental results.

\section{Numerical model}

All the numerical work is done using the 3D Computational Fluid Dynamics commercial code Ansys Fluent ${ }^{\mathrm{TM}}$. This software allows computing flow characteristics (flow velocity and turbulence quantities) dynamically in time or with a steady method over a spatial grid. It is based on a finitedifference solution of the Navier-Stokes equation with, in our case, a Shear Stress Transport (SST) $k-\omega$ turbulence closure scheme.

The method used to model the oyster table is first presented before being validated from the experimental data.

\subsection{The modeling method}

Oyster bags are a complex obstacle to the flow: the size and the shape of the oysters inside the bags are all different and randomly distributed. Moreover, the bags are a porous medium for which a fine representation seems to be needed. The accurate modeling of the bags filled with oyster inside being unreachable, an equivalent representation (with regards to the flow) has to be used in the model. We have made the choice to use Ansys Fluent ${ }^{\mathrm{TM}}$ with which it is possible to consider either a roughness approach or a porous approach, or both at the same time. These two approaches should normally be taken into account for the simulation of the real physical configuration. Unfortunately, a numerical model using rough and porous approaches simultaneously is very expensive in term of cells number and computational time. Each approach has therefore been investigated individually. 
Results obtained with a "realistic" table modeling for which oyster bags geometry is physically modeled are not satisfying (figure 9). The roughness law based on a physical roughness length and the dimensionless roughness constant used in the near wall region of the bags, considered as hermetic volumes, are not sufficient to give good results: velocity deficits are underestimated with differences up to $30 \%$ between the numerical and experimental results.

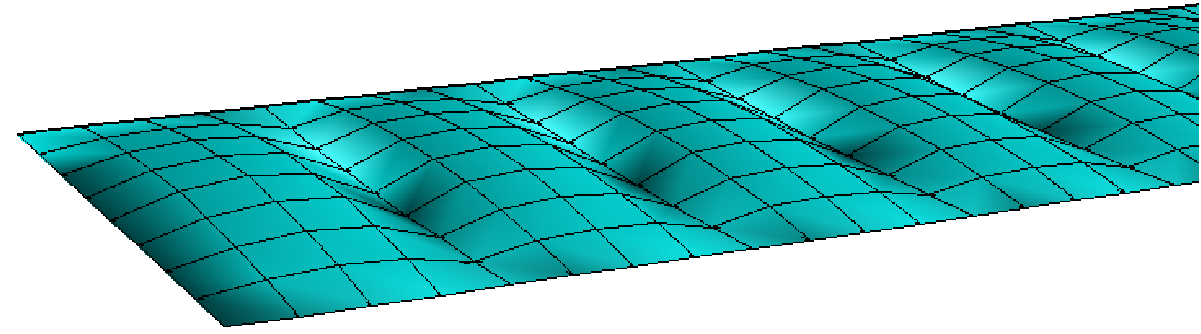

Figure 9: Numerical shape of the rough oysters bags

These results show that the flow interaction effects inside the oyster bags should be taken into account.

Following the approach of Plew et al. [12] and more recently of Delaux et al. [13], who modeled long-lines mussel farms by a uniform friction term spread over the whole rectangular long-line area, a "simplified" table approach is considered. The oyster table is divided in three simplified porous regions: one for the oysters bags and two others in order to take into account the legs of the table (figure 10).

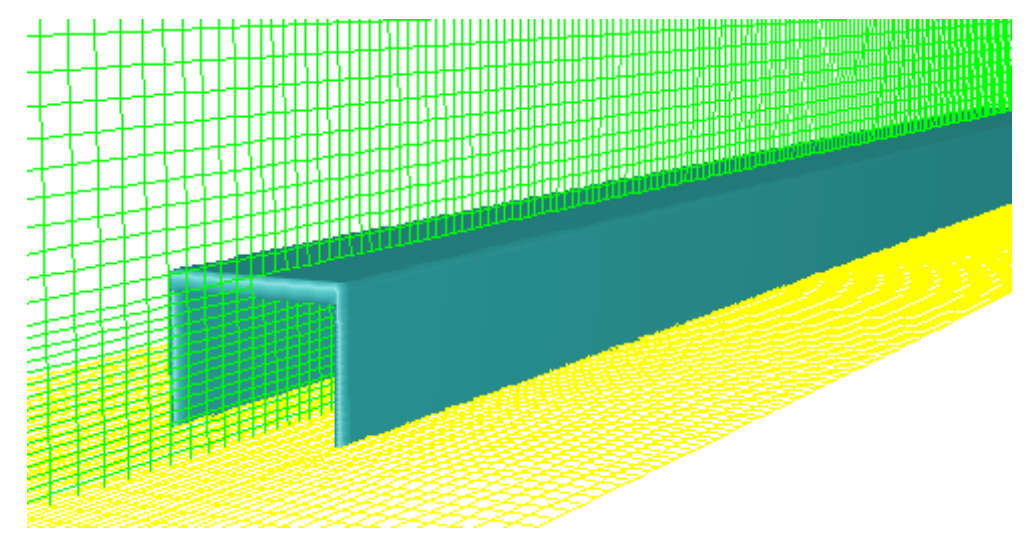

Figure 10: Mesh around the "simplified" oyster table with the porous legs 
Porous media are modeled in Ansys Fluent ${ }^{\mathrm{TM}}$ by the addition of a momentum source term (equation 3) to the standard fluid flow equations, composed of two parts: a viscous loss term from Darcy's law [14] and an inertial loss term from Forchheimer's correction for non-laminar flows [15] as expressed by the equation 3 .

$$
S_{i}=-\left(\frac{\mu}{\alpha} v_{i}+C_{2} \frac{1}{2} \rho\left|v_{i}\right| v_{i}\right)
$$

where $S_{i}$ is the source term for the $i t h$ momentum equation $(\mathrm{Pa} / \mathrm{m}), \mu$ is the dynamic viscosity (Pa.s), $\left|v_{i}\right|$ is the velocity magnitude $(\mathrm{m} / \mathrm{s}), \alpha$ is the permeability $\left(\mathrm{m}^{2}\right), \rho$ is the density of the fluid $\left(\mathrm{kg} / \mathrm{m}^{3}\right)$ and $C_{2}$ is the inertial resistance factor $(1 / m)$. This momentum sink contributes to the pressure gradient in the porous cell, creating a pressure drop that is proportional to the fluid velocity (or squared velocity) in the cell. The model solves the standard conservation equations for turbulence quantities in the porous medium. In this approach, turbulence in the medium is treated as though the medium has no effect on the turbulence generation or dissipation rates $[16,17]$.

Real table legs are vertical cylinders of $35 \mathrm{~mm}$ height and $8 \mathrm{~mm}$ diameter spaced by $60 \mathrm{~cm}$. A $7.20 \mathrm{~m}$ table has 12 legs on each side. But due to the difference of scale between the size of the table and the diameter of the legs, it would be difficult and very expensive in terms of cells to properly mesh the legs. The solution proposed here is to simplify the mesh of the legs by simply modeling them as two porous $8 \mathrm{~mm}$ thick vertical parallelograms (figure 10). The coefficients used for the modeling of the legs are given in table 1 , as well as those used for the oysters bags. The same set of parameters is used for each configurations $\mathrm{A}, \mathrm{B}$ and $\mathrm{C}$ because the oyster table is fixed in the frame of reference for the numerical model. This is the flow direction which changes for each configuration, on the contrary to the experimental setup (figure 11).

The porous coefficients for the table legs are null for $O y$ and $O z$ direction because, according to the experimental results (figure 6), the legs seem to have no influence on configuration $\mathrm{C}$ : it is the alignment effect of the legs in the flow direction which contributes to enlarge the wake under the table in configuration A. 


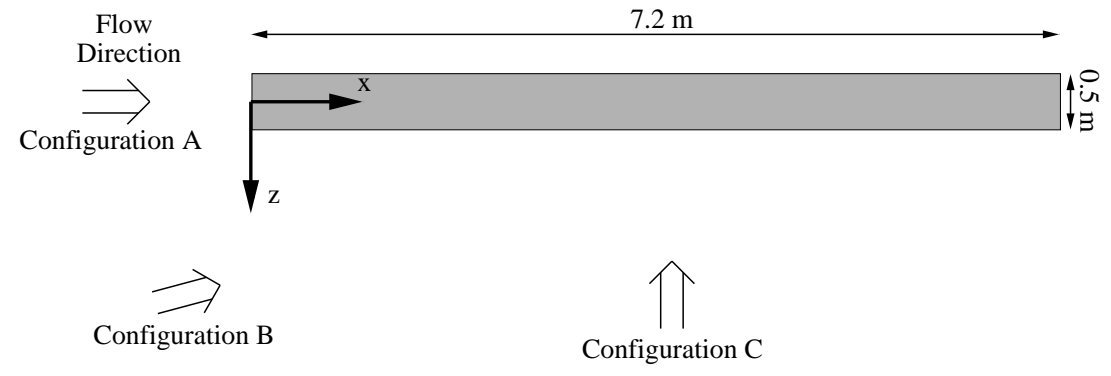

Figure 11: Presentation of configurations used for the numerical model (top view)

Table 1: Permeability and inertial resistance factors chosen for the oyster bags and table legs along each axis

\begin{tabular}{c||c|c||c|c}
\multicolumn{1}{c||}{} & \multicolumn{2}{c||}{ oysters bags } & \multicolumn{2}{c}{ table legs } \\
\hline Axe & $1 / \alpha\left[\mathrm{m}^{-2}\right]$ & $C_{2}\left[\mathrm{~m}^{-1}\right]$ & $1 / \alpha\left[\mathrm{m}^{-2}\right]$ & $C_{2}\left[\mathrm{~m}^{-1}\right]$ \\
\hline \hline $\mathrm{X}$ & 4 & 10000 & 4 & 0 \\
\hline $\mathrm{Y}$ & 0 & 1000000 & 0 & 0 \\
\hline $\mathrm{Z}$ & 4 & 10000 & 0 & 0
\end{tabular}

\subsection{The modeling scheme}

The calculation of the Reynolds number of the flow around the experimental model of the oyster table clearly shows that the numerical model needs a turbulence closure scheme:

$$
R e=\frac{U L}{\nu}=3.6 .10^{6}
$$

with $U=0.5 \mathrm{~m} / \mathrm{s}, L=7.2 \mathrm{~m}$ the length of the table and $\nu=1.10^{-6} \mathrm{~m}^{2} / \mathrm{s}$. In order to study the boundary layer development and the flow in the wake of the table, the SST $k-\omega$ model [18] is selected. This accurate and robust model has the same form as the classical $k-\omega$ model with two transport equations for the turbulent kinetic energy $k$ and the specific dissipation rate $\omega$. The two major ways in which the SST model differs from the classical model are: 1) a gradual change from the standard $k-\omega$ model in the inner region of the boundary layer to a high Reynolds number version of the $k-\varepsilon$ model in the outer part of the boundary layer and 2) a modified turbulent viscosity formulation to account for the transport effects of the principal turbulent shear stress.

The steady segregated solver is used to solve the SST $k-\omega$ model. In 
the segregated algorithm the governing equation is solved sequentially, so the solution loop must be carried out iteratively in order to obtain a converged numerical solution. This solver solution based on the pressure is adapted to low speed flows [19]. The second-order upwind discretization scheme is chosen: it requires longer calculation times than the first order one but is more robust. The Semi-Implicit Method for the Pressure-Linked Equation (SIMPLE) is chosen for the pressure-velocity coupling method.

The calculation is here considered as converged when every scaled residuals are lower than $1.10^{-4}$.

\subsection{Computational grid}

A three dimensional numerical flume tank is considered in order to simulate the experimental conditions. The total height of the domain is two meters and the width is four meters. The length of the numerical tank is $11.20 \mathrm{~m}: 2 \mathrm{~m}$ upstream and $2 \mathrm{~m}$ downstream from the $7.20 \mathrm{~m}$ table.

A roughness effect is considered on the bottom wall to reproduce the evolution of the bottom boundary layer along the domain. This parameter modifies the law-of-the-wall function near the boundary: the slope is the same but it changes the intercept by adding a constant in the log-law depending on the type and on the size of the roughness.

The relatively short upstream distance of $2 \mathrm{~m}$ before the table is only possible by introducing a velocity profile in the inlet boundary condition. This profile is extracted from the experimental data and reproduce the bottom boundary layer observed in the tank at that point. Without this inlet velocity profile, a length of around $10 \mathrm{~m}$ long upstream from the table should be needed to simulate correctly the full development of the bottom boundary layer of the tank.

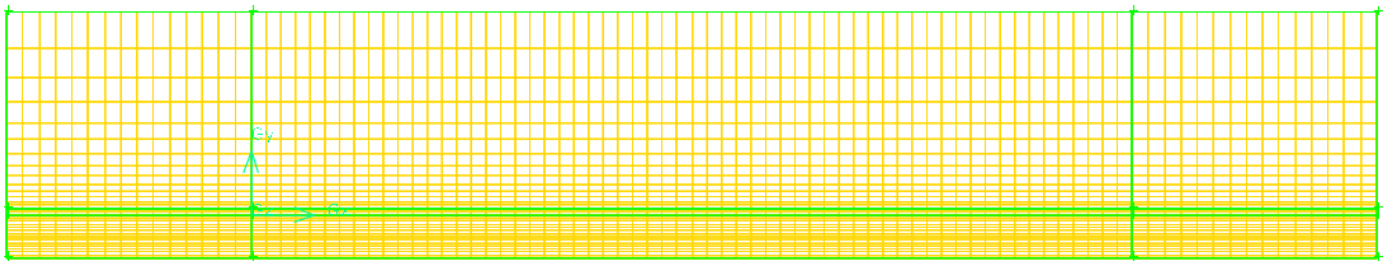

Figure 12: Side view and cells distribution of the numerical domain

The domain grid is created using the so called mapped mesh scheme since it results in a more structured mesh than with tetrahedral elements (figure 
12). The domain is divided into 18 sub-domains in order to refine the cell size in the near-wall regions, close to the table and the bottom. Actually, these areas contain high velocity gradients and require a more refined mesh. Moreover, the division in several domains reduces the mesh skewness and allows a better global homogenization of the mesh size.

The size of the first cell depends on the roughness parameter. It is not physically meaningful to have a mesh size such that the wall-adjacent cell is smaller than the roughness height. A comparison of many velocity profiles and experimental data for different first mesh sizes shows that the domain has to be refined especially between the bottom and the lower surface of the table in the vertical direction. The upper surface of the table is less dependent on the first cell size. This is explained by the fact that the bottom is a wall which required to be finely meshed for the development of the boundary layer, whereas the table is a porous medium.

To check the effect of the first cell size above the bottom wall, and so of the global number of cells of the domain, the dimensionless parameter $y^{+}$is used. This parameter is defined with the following equation:

$$
y^{+}=\frac{\rho u^{*} d}{\mu}
$$

with $\rho$ the density, $u^{*}$ the friction velocity, $d$ the wall distance in the normal direction of the wall boundary and $\mu$ the viscosity.

Results of this comparison are shown on figure 13. The tested cases do not exhibit significant differences, except for the highest $y^{+}$values $\left(y^{+}>40\right)$. The value $y^{+}=20$ is chosen for simulations because of the good agreement with the experimental velocities and the reasonable number of cells.

The length of the cells (in the flow direction) was also tested: from 720 to 8 cells along the table. The results show that the mean differences between experimental and numerical velocities vary from 5.9 to $6.3 \%$ on 5 different profiles along the table. The mesh with 120 cells along the table is kept because of the good compromise between the mesh quality and the calculation time.

These choices lead to a 205000 cells three dimensional numerical domain. This relatively small number of cells permits to run the numerical model on a classical Personal Computer with a computational time of about 20 minutes for a steady case. 


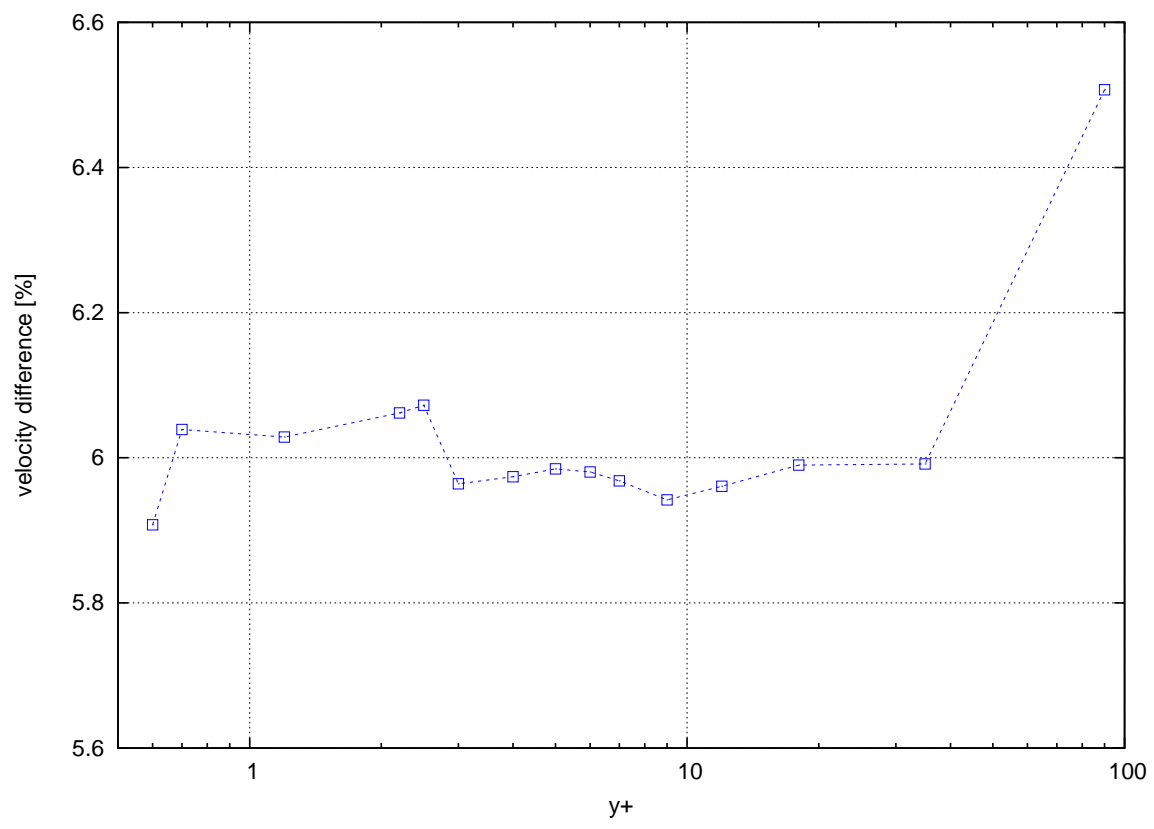

Figure 13: Mean difference of velocity along the vertical profiles, for configuration A, between experimental and numerical data for different meshes with various $y^{+}$values

\subsection{Numerical model validation}

Figures 14, 15 and 16 show the numerical results along the table and in the wake for configurations $\mathrm{A}, \mathrm{B}$ and $\mathrm{C}$ respectively. The comparison with the experimental data is shown on these figures in terms of reduced velocity, which is the ratio between the velocity at the considered point and the far upstream velocity $V_{i n f}=0.5 \mathrm{~m} . \mathrm{s}^{-1}$. The difference $\Delta V$ expressed in $\%$ on these figure is the ratio between the difference of velocities (experimental $V_{\exp }$ and numerical $V_{\text {num }}$ ) and the experimental velocity for the considered point:

$$
\Delta V=\frac{V_{\text {exp }}-V_{\text {num }}}{V_{\text {exp }}}
$$

These comparisons are made on the locations presented on figures 4 by 6 blue points for each configuration A, B and C.

For configuration A (figure 14), the numerical velocities are in quite good agreement with the experimental data, in the center of the table $(\mathrm{z}=0 \mathrm{~m})$ as well as $5 \mathrm{~cm}$ away from the side of the table $(\mathrm{z}=0.30 \mathrm{~m})$.

Some differences appear, especially around the table. Under the table, for 

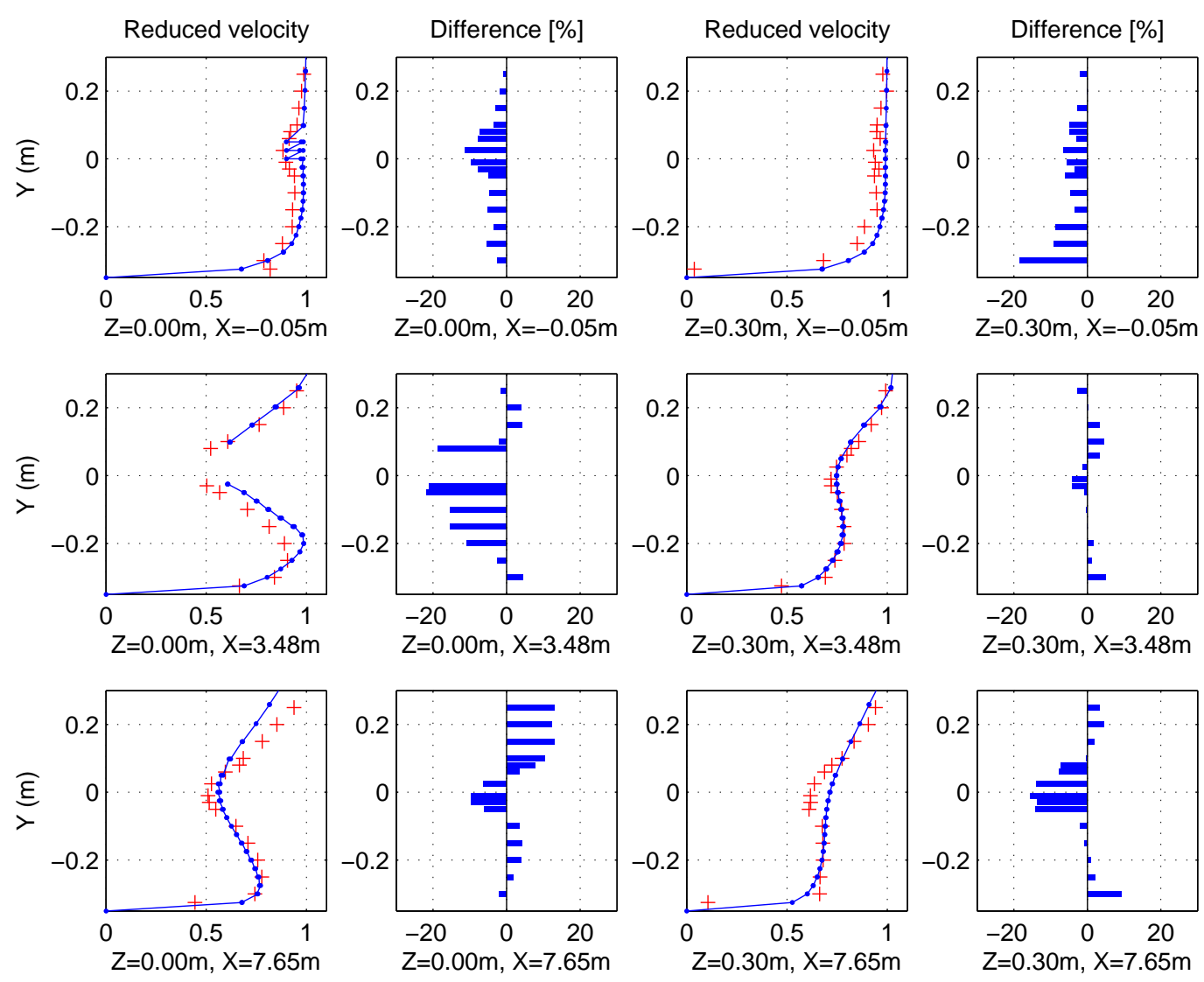

Figure 14: Comparison of the reduced velocity profiles for the numerical table and experimental results obtained for configuration $\mathrm{A}$, at $\mathrm{Z}=0 \mathrm{~m}$ (left) and $\mathrm{Z}=0.30 \mathrm{~m}$ (right) and $\mathrm{X}=[-0.05 ; 3.48 ; 7.65] \mathrm{m}$, i.e. points 1 to 6 on figure $4(\mathrm{a})$. On the left: reduced velocity profiles (red crosses: experimental results, blue lines and points: numerical results), on the right: difference $(\%)$.

$\mathrm{z}=0 \mathrm{~m}$ and $\mathrm{x}=3.48 \mathrm{~m}$, the numerical velocities are about $15 \%$ higher than the experimental data. On the contrary, above the table, for $\mathrm{z}=0 \mathrm{~m}$ and $\mathrm{x}=$ $7.65 \mathrm{~m}$, the numerical velocities are about $15 \%$ lower than the experimental data. But these differences are localized and do not affect the global profile. They are, all around the table, lower or equal to $15 \%$. The differences are highest near the table, as it is shown for $\mathrm{z}=0 \mathrm{~m}$ and $\mathrm{x}=3.48 \mathrm{~m}$ at $\mathrm{y}=-0.05$ $\mathrm{m}$, whereas the numerical velocities are at the most accurately reproduced at $\mathrm{y}=-0.2 \mathrm{~m}$. Actually, the difference between the numerical and experimental velocity is quite constant for these two points, but the experimental velocity 
is lower at $\mathrm{y}=-0.05 \mathrm{~m}$, so $\Delta V$ is higher than at $\mathrm{y}=-0.2 \mathrm{~m}$.

The mean velocity difference for this configuration is $5.99 \%$.
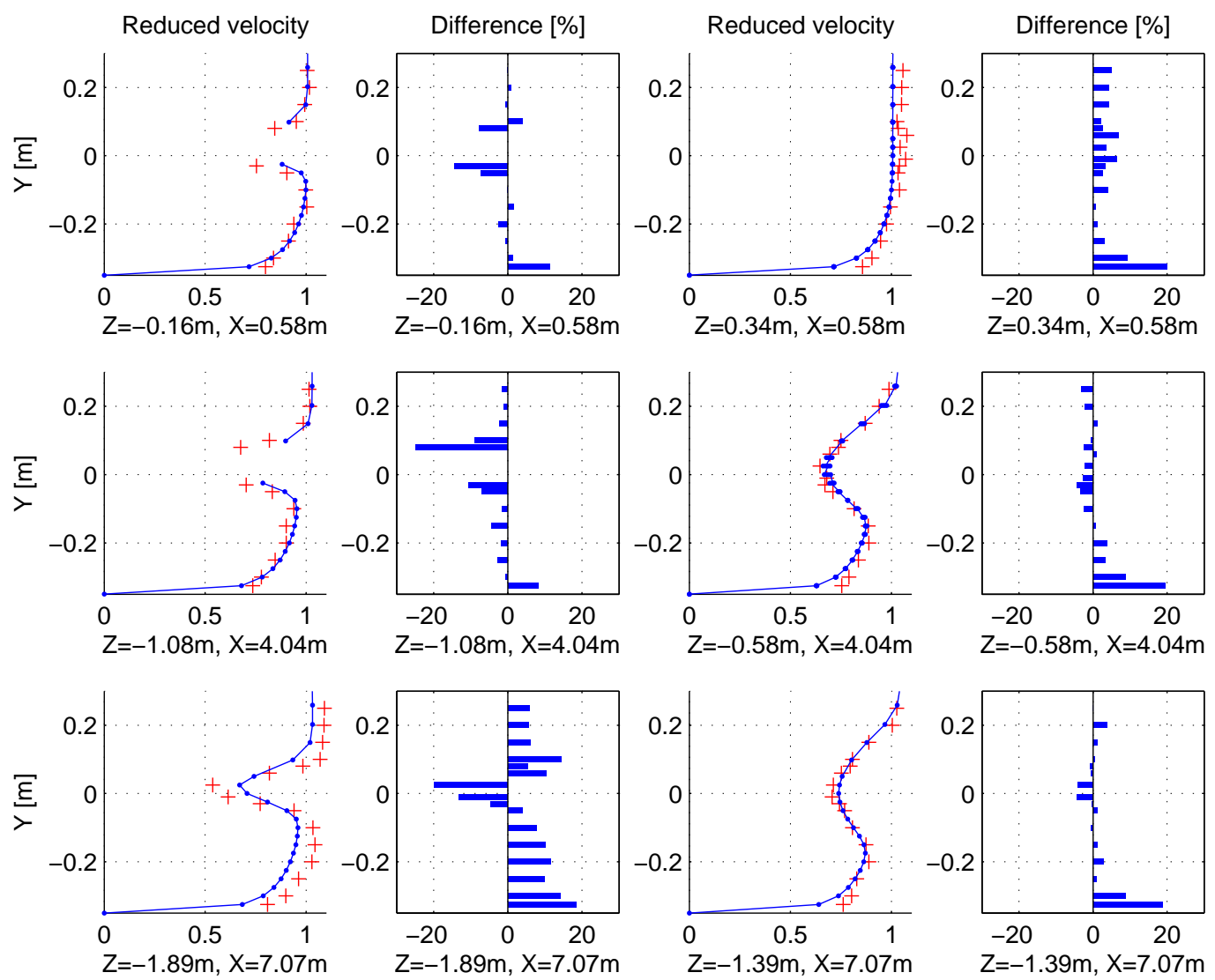

Figure 15: Comparison of the reduced velocity profiles for the numerical table and experimental results obtained for configuration $\mathrm{B}$, at $\mathrm{Z}=[-0.16 ;-1.08 ;-1.89] \mathrm{m}$ (left) and $\mathrm{Z}$ $=[0.34 ;-0.58 ;-1.39] \mathrm{m}$ (right) for $\mathrm{X}=[0.58 ; 4.04 ; 7.07] \mathrm{m}$, i.e. points 1 to 6 on figure 4(b). On the left: reduced velocity profiles (red crosses: experimental results, blue lines and points: numerical results), on the right: difference (\%).

Comparisons of data for configuration B (figure 15) lead to quite similar results as for configuration A. The differences between the numerical and experimental results are fairly small for every presented profiles. They are always lower or equal to $5 \%$, except for the profile at $\mathrm{z}=-1.89 \mathrm{~m}$ where the numerical velocities are under-estimated all along the profile by about $10 \%$. 
Once again, for most profiles, the differences are higher near the bottom and just under or above the table, and they reach $20 \%$.
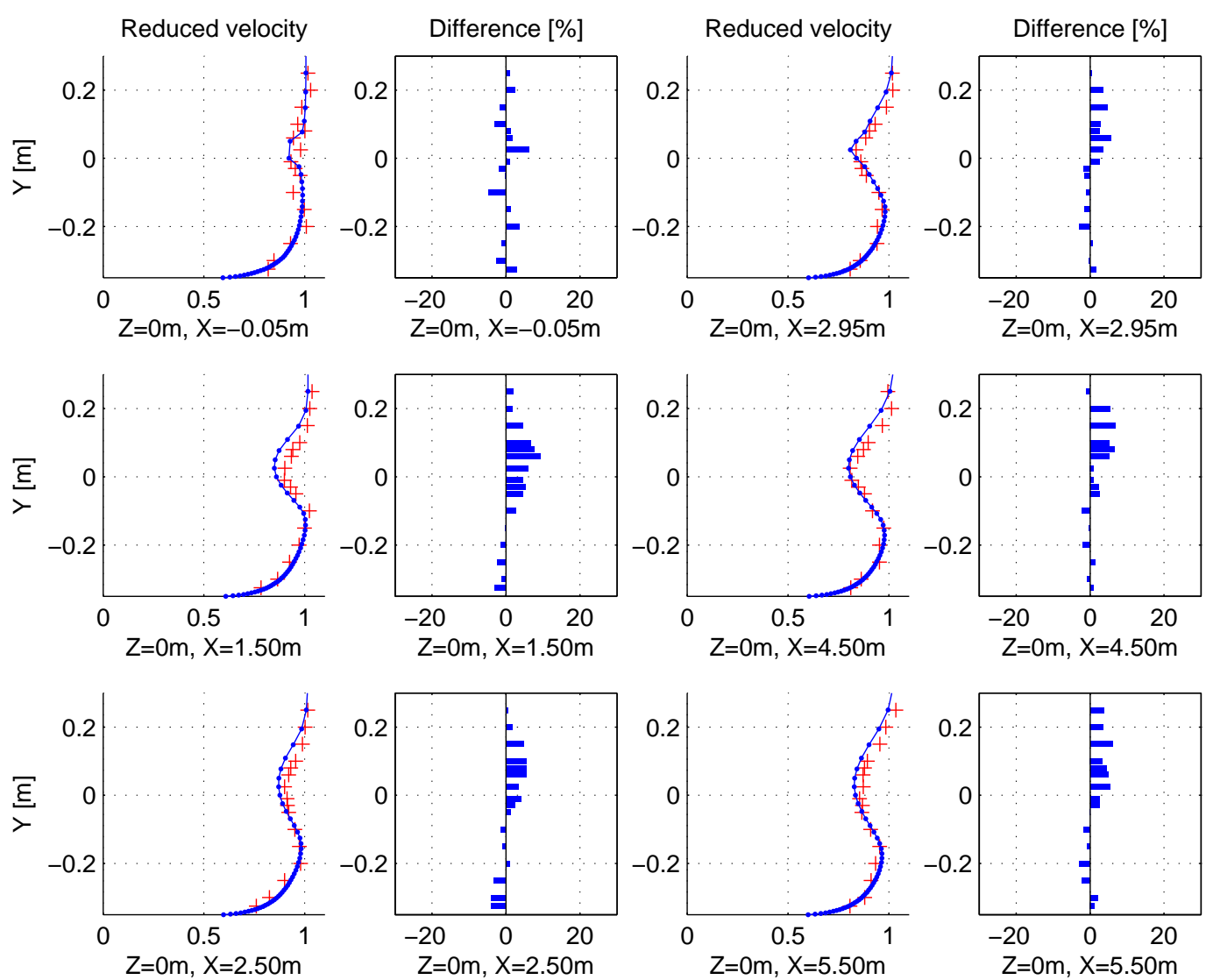

Figure 16: Comparison of the reduced velocity profiles for the numerical table and experimental results obtained for configuration $\mathrm{C}$, at $\mathrm{Z}=0 \mathrm{~m}$ and for $\mathrm{X}=[-0.05 ; 1.50 ; 2.50$; $2.95 ; 4.50 ; 5.50] \mathrm{m}$, i.e. points 1 to 6 on figure $4(\mathrm{c})$. On the left: reduced velocity profiles (red crosses: experimental results, blue lines and points: numerical results), on the right: difference $(\%)$.

The evolution of the profiles is different for configurations $\mathrm{A}$ and $\mathrm{B}$. The wake in the middle of the table $(\mathrm{z}=-0.16,-1.08$ and $-1.89 \mathrm{~m})$ is much smaller and less developed in configuration $\mathrm{B}$ than for the previous configuration. These three profiles are quite similar with an evolution versus the vertical axis which is the same, except for the amplitude of the velocity which is lower at $\mathrm{x}=4.04 \mathrm{~m}$ for the experimental data. This similarity of the vertical profiles results from $15^{\circ}$ orientation of the table, which makes the length of 
the table become a leading edge for the flow.

On the side of the table $(\mathrm{z}=0.34,-0.58$ and $-1.39 \mathrm{~m}$, figure 15$)$, except for the first profile $(\mathrm{x}=0.58 \mathrm{~m})$ which is not in the wake, the velocity deficit is also quite the same for $\mathrm{x}=-4.04 \mathrm{~m}$ and $\mathrm{x}=7.07 \mathrm{~m}$. The last profile ( $\mathrm{x}$ $=7.07 \mathrm{~m}$ ) is larger than the profile at $\mathrm{x}=4.04 \mathrm{~m}$, but the amplitude of the deficit is constant about $40 \%$, just at the level of the table $(\mathrm{y}=0.05 \mathrm{~m})$. Contrary to configuration A, where the wake of the legs is noticeable between the bottom and the table on the side $(\mathrm{z}=0.30 \mathrm{~m}$ and $\mathrm{x}=7.65 \mathrm{~m}$, figure 14) with a velocity deficit of about $40 \%$ at $\mathrm{y}=-0.2 \mathrm{~m}$, it is not clearly the case here. The velocity deficit reaches only $20 \%$ at $\mathrm{z}=-1.39 \mathrm{~m}$ and $\mathrm{x}=7.07 \mathrm{~m}$ for the same altitude. This remark confirms that the alignment of the legs with the flow is indeed responsible for the wake. It also confirms the choice of using porous factors for the legs in the direction of the table only.

For configuration $\mathrm{C}$, the numerical velocities are in good agreement with the experimental data. Differences are everywhere lower than $10 \%$. The maximum of difference is reached in the wake behind or just above the table, for $\mathrm{y}$ between 0 and $0.2 \mathrm{~m}$, for example at $\mathrm{x}=1.50 \mathrm{~m}$ or $\mathrm{x}=4.50 \mathrm{~m}$. Except for these locations, differences are lower than $5 \%$.

For this last configuration, it is interesting to compare the wake development behind the first and the second table (first and third column on figure 16). There is no significant difference between the bottom wall and the tables $(-0.35 \mathrm{~m}<\mathrm{y}<0 \mathrm{~m})$. The slope of the boundary layer is the same and the velocity deficit is comparable for a given distance behind the first or the second table. This is not the case for $\mathrm{y}>0 \mathrm{~m}$. Actually, the wake is larger and higher behind the second table, with a velocity deficit amplitude more pronounced. This suggests a slight wake interaction for this distance between the tables.

In configuration $\mathrm{C}$, the legs do not have any influence on the wake. The velocity deficit at $\mathrm{y}=-0.2 \mathrm{~m}$ is close to zero for all profiles, which means that the velocity between the bottom and the table reaches the upstream velocity, instead of the boundary layer on the bottom and under the table.

Figure 17 shows the Turbulent Kinetic Energy for the $7.20 \mathrm{~m}$ table on the median vertical plane for configurations $\mathrm{A}, \mathrm{B}$ and $\mathrm{C}$.

These maps of TKE are compared to the experimental maps shown on figure 7 . For configuration A, the numerical TKE shows a large development above the table, with high values around $7.10^{-3} \mathrm{~m}^{2} / \mathrm{s}^{2}$. It is also the case 


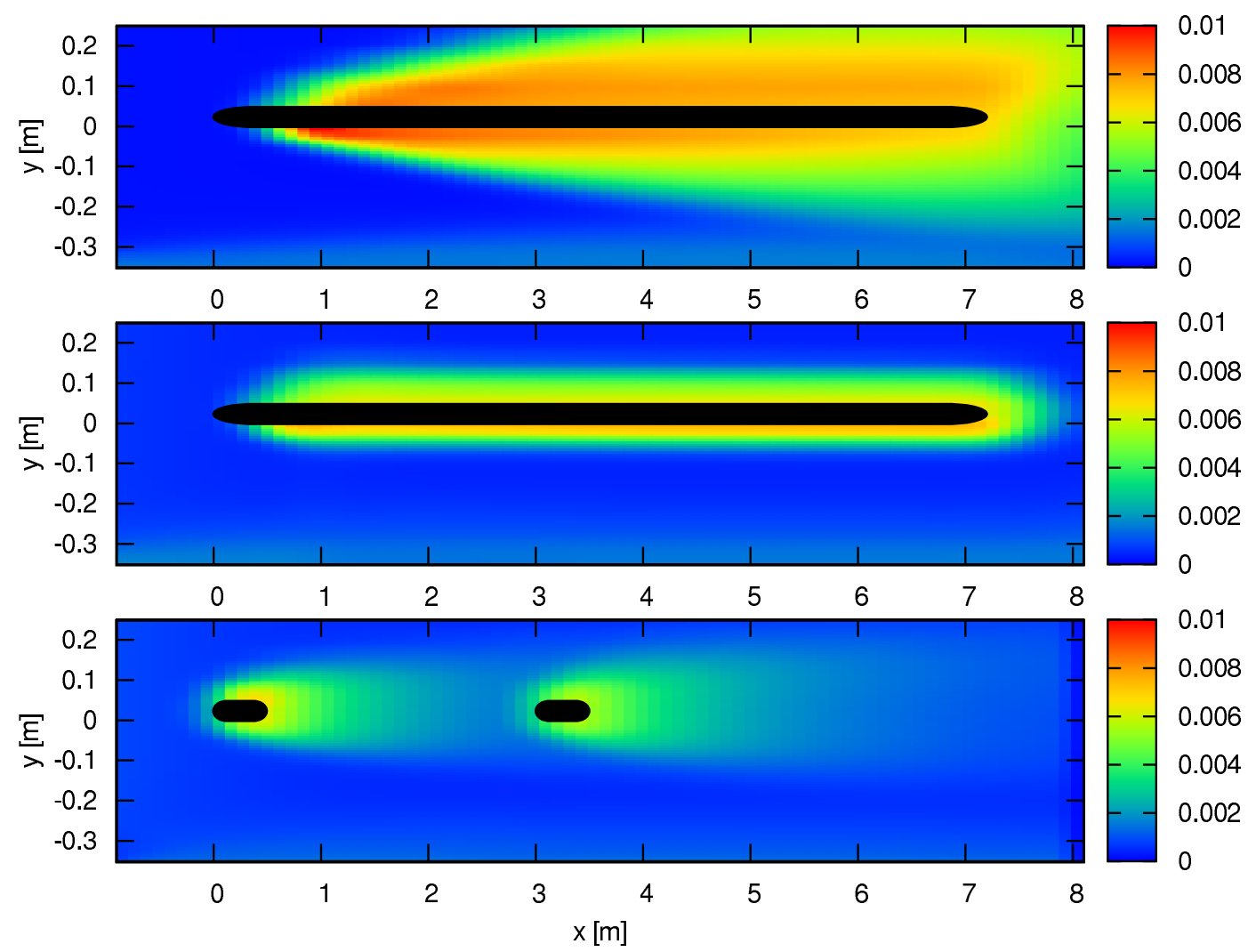

Figure 17: Turbulent Kinetic Energy $\left(\mathrm{m}^{2} / \mathrm{s}^{2}\right)$ on the median vertical plane for numerical tables in configurations A (top), B (middle) and C (bottom)

for the experimental TKE, but with lower values around $5.10^{-3} \mathrm{~m}^{2} / \mathrm{s}^{2}$. For configuration B, high TKE values surround the table but the amplitudes are larger for the experimental data $\left(\simeq 9 \cdot 10^{-3} \mathrm{~m}^{2} / \mathrm{s}^{2}\right)$ than for the numerical results $\left(\simeq 7.10^{-3} \mathrm{~m}^{2} / \mathrm{s}^{2}\right)$. This is also the case for configuration $\mathrm{C}$, where the experimental TKE shows a larger intensity $\left(\simeq 7.10^{-3} \mathrm{~m}^{2} / \mathrm{s}^{2}\right)$ than the numerical results $\left(\simeq 5 \cdot 10^{-3} \mathrm{~m}^{2} / \mathrm{s}^{2}\right)$. The area of high TKE values is larger for the second table than for the fist one, especially above the table, in both the experimental and numerical data. From all these results, we can consider that, even if some slight differences are observed close to the tables, the near field obtained with the numerical model is calibrated and validated thanks to the experimental data based on a $7.20 \mathrm{~m}$ long table.

In common oyster farms, tables are about $100 \mathrm{~m}$ long and are often grouped. Results presented in the next section represent a first step in the 
numerical modeling of full-length oyster tables. Since there are no experimental or in-situ measurements of the velocity in this real configuration, results must be carefully considered.

\section{Real length table modeling}

\subsection{Extension of the model}

In order to reproduce realistic lengths encountered in the field, the model has to be extended. Simulating a real length table with the same refinement as the $7.20 \mathrm{~m}$ table would require to adapt the grid to the new configuration, which would drastically increase the computation domain. Ansys Fluent ${ }^{\mathrm{TM}}$ allows to avoid this constraint thanks to a scaling technique: a scale factor can be defined in each direction in order to modify the grid size. The size of the modeled structure can therefore be increased while keeping the same number of grid points. If different scale factor are used in both directions, this technique changes the cell aspect ratios, which cannot be done without caution. However, in our case simplified mesh with porous bags and legs proposed in the previous section is appropriate to the scale factor because it can be easily extended without any geometric modifications.

Two grids are investigated in order to check the effect of the scale factor on the results. Comparisons are made between the results obtained with the mesh of the $7.20 \mathrm{~m}$ porous table scaled with a scale factor of ten in the flow direction (205 000 cells) and a grid for a $72 \mathrm{~m}$ long table with the same distribution and cells size as the $7.20 \mathrm{~m}$ table grid (1 663000 cells). Several velocity profiles are compared along the two tables. Figure 18 shows these velocity comparisons.

These profiles are in excellent agreement all along the tables. Only a slight difference is noticeable for the first profiles $(\mathrm{X}=10.29 \mathrm{~m})$ under the table. This agreement results from the large length of the table, from the alignment of the flow with the table and from the low intensity of the turbulence $(5 \%)$. These results, validate the use of the scale factor in this configuration.

So, for a real size of $100 \mathrm{~m}$ long table, the mesh of a $10 \mathrm{~m}$ long table is done with the same cell sizes described in the previous section. Then a scale factor of 10 is applied in the flow direction. The velocity of the full-scale

table is $0.7 \mathrm{~m} . \mathrm{s}^{-1}$ and the boundary layers are similar to those of the $1 / 2$ scale table. 

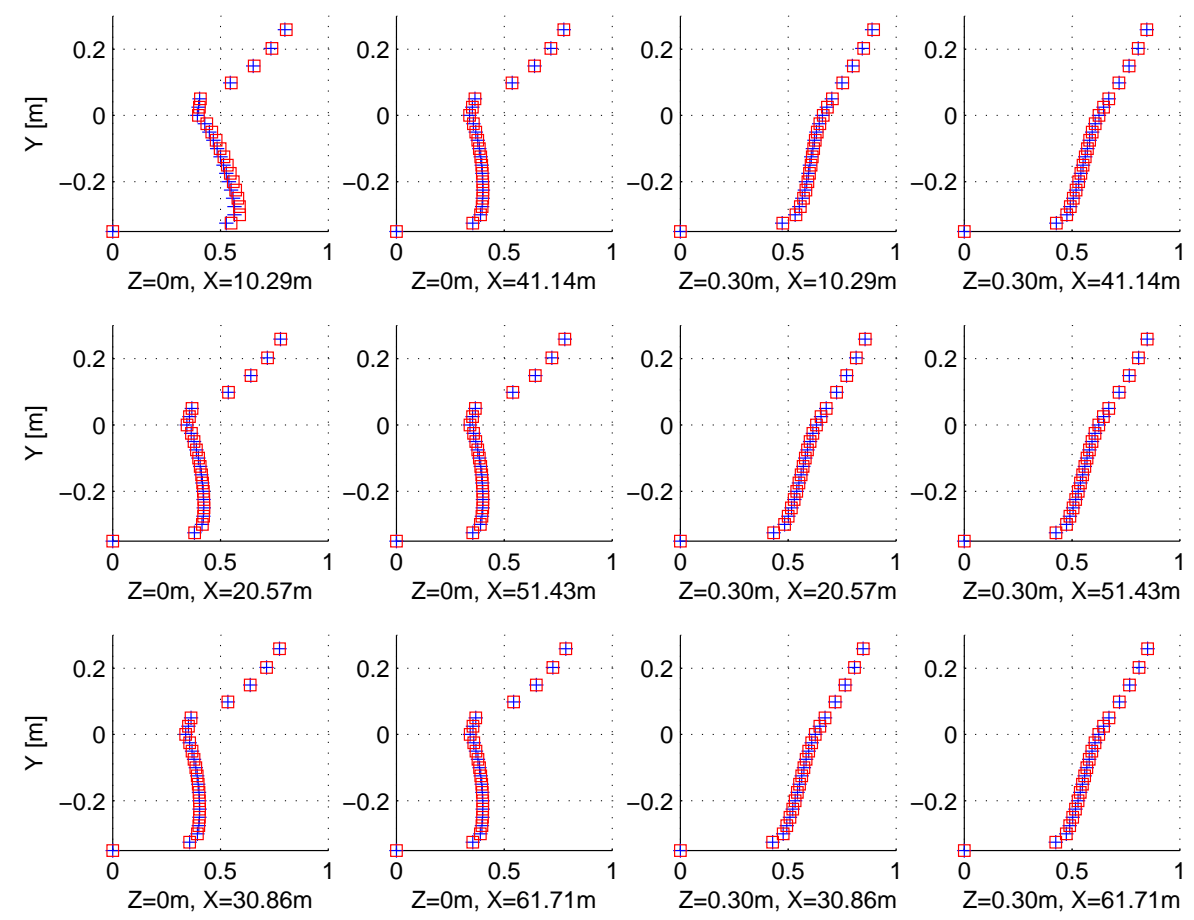

Figure 18: Comparison between numerical velocity profiles for an extended table of $10 \times$ $7.20 \mathrm{~m}$ long table (blue crosses) and $72 \mathrm{~m}$ long table (red squares)

Figure 19 investigates the velocity profiles along a full-scale $100 \mathrm{~m}$ long table in configuration aligned with the flow. The evolution of the velocities is quite different from the one along the $1 / 2$ scale $7.20 \mathrm{~m}$ long table. Indeed, the wake is growing fast during the first $20 \mathrm{~m}$ then stabilizing for the rest of the table. On figure 18 , from $\mathrm{X}=20.57 \mathrm{~m}$, all vertical velocity profiles are similar. Under the table, both the boundary layers of the bottom and of the table are joining together from about $30 \mathrm{~m}$. After that, there is no more evolution in the vertical wake, which is fully developed.

The bottom shear stress extracted from this simulation is essential in order to understand the modifications of the sediment dynamics inherent to the presence of the oyster table. As shown on figure 20(a), it allows to forecast the area where sedimentation may occur around a table in this configuration.

Depending on the type of sediment located in the area and the associated critical shear stress value for erosion, sediment could be put in suspension for the highest shear stresses. According to [20], the critical shear stress is 


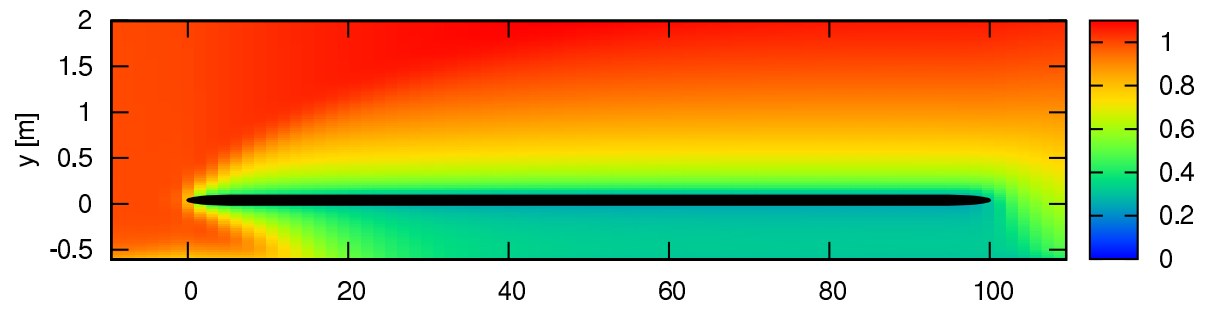

Figure 19: Vertical maps of the reduced longitudinal velocity in configuration aligned with the flow for a full-scale $100 \mathrm{~m}$ long table in the plane $\mathrm{z}=0 \mathrm{~m}$ (center of the table)

strongly dependent on the volume fraction of mud and clay on the sediment, but can vary between $0.2 \mathrm{~Pa}$ and $2 \mathrm{~Pa}$ in this kind of tidal flats. So, sedimentation appears when the shear stress is under this critical shear stress value. And in this case, figure 20(a) points out possible sedimentation under and behind the table, with shear stresses under $0.2 \mathrm{~Pa}$, like what happens in the Baie-des-Veys, France (figure 20(b)). The bottom shear stress is the lowest in the middle of the table and from $\mathrm{X} \simeq 40 \mathrm{~m}$, with values under $0.1 \mathrm{~Pa}$, when the wakes of the two legs alignments and the table is fully developed and merged.

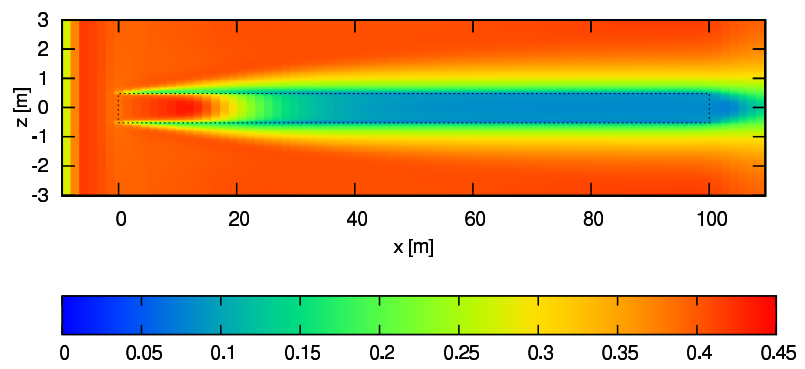

(a)

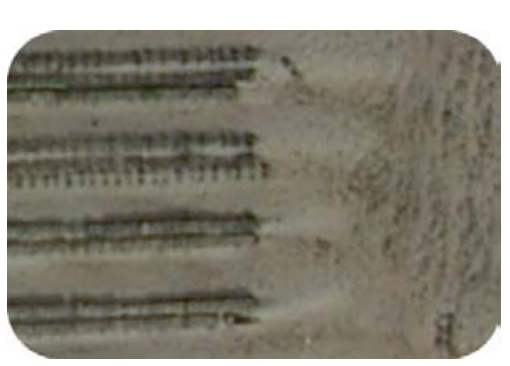

(b)

Figure 20: Contours of bottom shear stress (Pa) under a $100 \mathrm{~m}$ long table (a) and top photography of four rows of two oyster tables in the Baie-des-Veys, France (b).

In an oyster farm, tables are often grouped by two (figure 20(b)), three or four with a space between each group wide enough for farm vehicles. Without modeling a complete oyster farm, numerical simulations of four tables grouped by two and $5 \mathrm{~m}$ apart give a good outline of the impact of many tables at a larger scale. The magnitude of the flow is always $0.7 \mathrm{~m} / \mathrm{s}$ 
and tables are aligned with the flow. Results, in term of reduced velocities, are shown on figure 21.

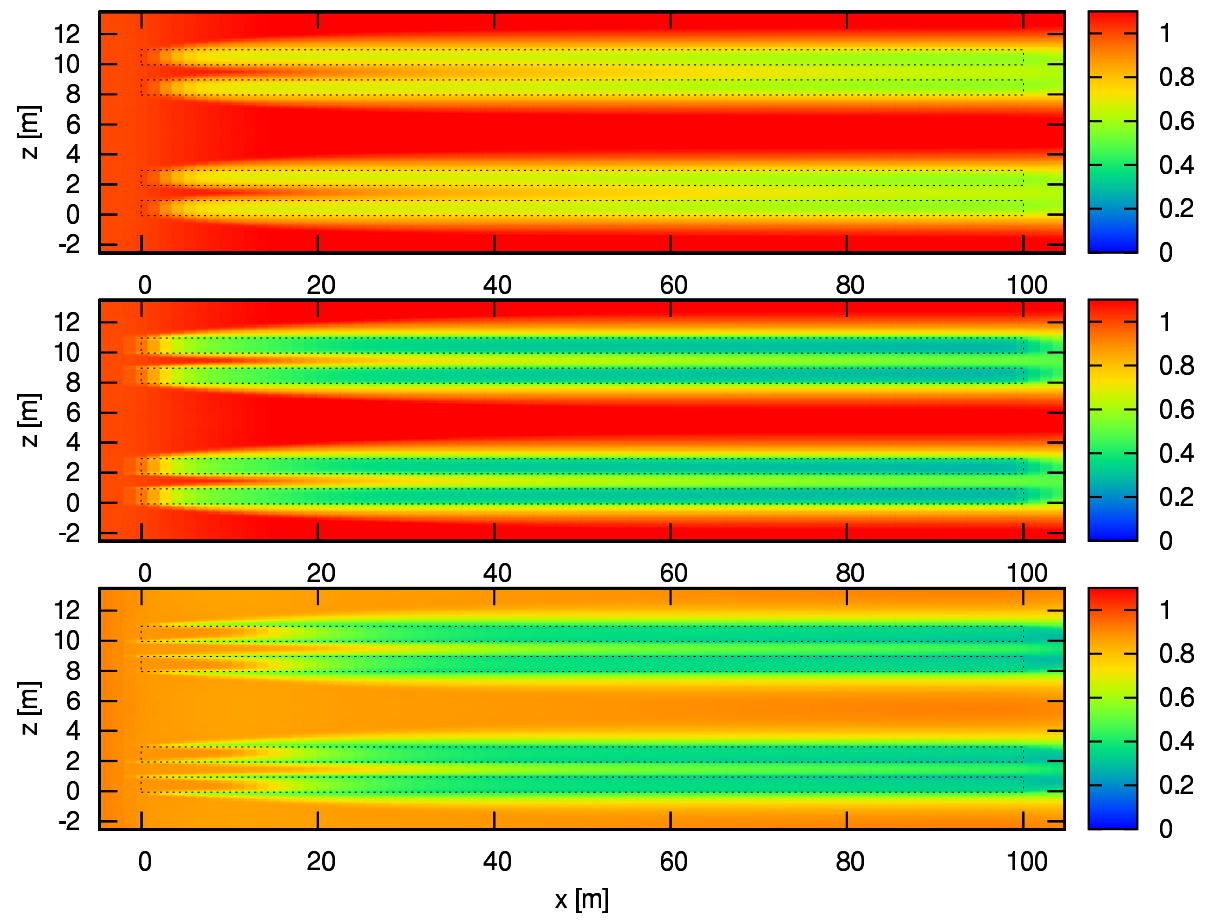

Figure 21: Horizontal maps of the normalized longitudinal velocity around four tables aligned with the mean flow direction, at $\mathrm{y}=0.3 \mathrm{~m}, \mathrm{y}=-0.1$ and $\mathrm{y}=-0.6 \mathrm{~m}$ from the top to the bottom

In this configuration, there is no wake interaction between two rows of tables. The distance between them seems to be too large. The wake is growing in the vertical direction more than in the horizontal direction. However, two tables in a row are so close compared to their length that their wakes merge at $\mathrm{X} \simeq 30 \mathrm{~m}$ between the bottom wall and the table, at $\mathrm{X} \simeq 50 \mathrm{~m}$ just under the table and $\mathrm{X} \simeq 90 \mathrm{~m}$ above the table. Once again, the wake develops faster and becomes larger under the table than everywhere else. This wake merging induces low velocities, less than $40 \%$ of the far upstream velocity, near the bottom and along half the length of the table.

For the same configuration but with the flow at $15^{\circ}$ from the axis of the tables (figure 22), the decrease of velocities is not too pronounced: it reaches only $20 \%$ above the table and $40 \%$ between the bottom and the table. For 


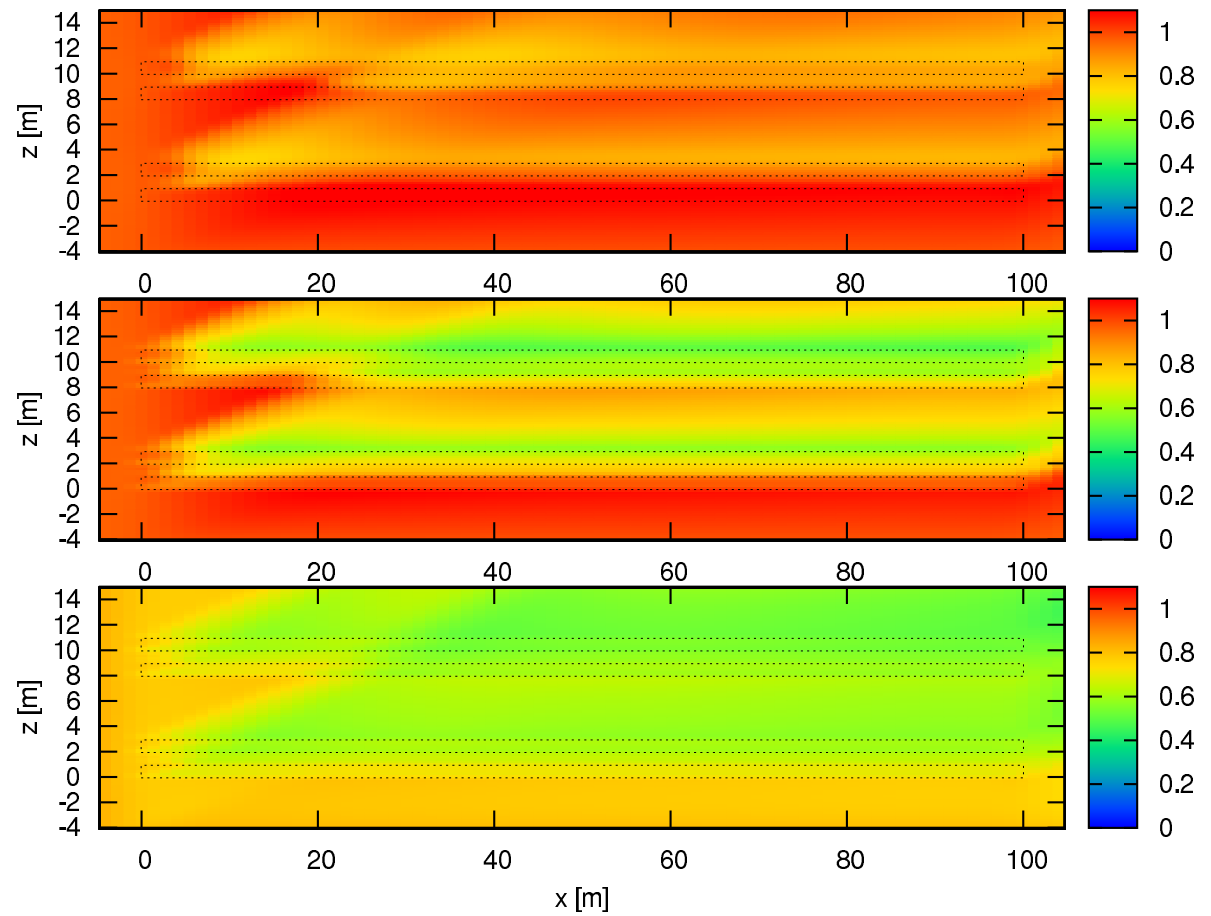

Figure 22: Horizontal maps of normalized longitudinal velocity around four tables with an angle between the mean flow direction and the tables' direction of $15^{\circ}$, at $\mathrm{y}=0.3 \mathrm{~m}$, $\mathrm{y}=-0.1$ and $\mathrm{y}=-0.6 \mathrm{~m}$ from the top to the bottom

this case, the wake is growing on the sides and merging appears between two tables of the same row from $\mathrm{X} \simeq 5 \mathrm{~m}$ to be as one. The wake coming from the first row interacts with the second row at $\mathrm{X} \simeq 20 \mathrm{~m}$, from where the velocity deficit increases slightly.

From this first set of simulations, a strong influence of the farm angle on the velocity is found. Interactions between tables and between rows of tables are observed on the wake development, depending on the orientation. According to these numerical results, the presence of oyster farm affects the environment in different ways. First, it induces energy dissipation which results in the reduction of the magnitude of the mean flow. Then, it creates velocity gradient in the near field of the tables responsible for high shear stresses.

The model presented here takes advantage of the porous media used to reproduce tables associated with the steady solver in time to provide simu- 
lations of the flow around an oyster farm in a short calculation time. This work gives motivation for new observations or in-situ measurements for comparisons.

\section{Conclusion}

Comparisons between several modeling configurations of an oyster table in the flow and experimental results have been investigated. The porous model presented here with the addition of the porous legs is in good agreement with the experimental results obtained in the tank at a scale of 1 to 2 and for a $7.20 \mathrm{~m}$ long table. The extension of this model to a real size of oyster tables allows the investigation of the hydrodynamic behavior of the flow around one or a small number of tables at a scale of 1 to 1 . Interactions between the wakes of the tables and bottom shear stresses are now numerically reachable for a part of an oyster farm in different configurations of incidence of the mean flow.

This way of modeling is a promising approach since it could be extended again to a largest size in order to model a whole oyster farm. But this model needs to be compared with in-situ hydrodynamics data before adding sediment dynamics in order to reproduce sedimentation effects. The impact of the waves should also be accounted for in order to improve the model.

Velocity and turbulence fields obtained by this kind of modeling could also be included into wide-extension hydrodynamic coastal models in order to reproduce the effects of an oyster farm on hydrodynamics and sediment dynamics at the scale of a bay. The first steps are presented in [11]. Once it will be achieved, this tool could provide an help to decide the best configuration in order to limit the siltation phenomenon.

\section{Acknowledgments}

The authors would like to acknowledge Jean-Valery Facq for the experimental device development and data acquisition, Mathieu Brevers for the first steps of the numerical work and Région Basse-Normandie for the financial support of the PhD work.

\section{References}

[1] S. Bahé, Conchyliculture et dynamique morpho-sédimentaire en baie du mont saint-michel, Master's thesis, EPHE (2003). 
[2] J. Sornin, Processus sédimentaires et biodéposition liés à différents modes de conchyliculture, Ph.D. thesis, Institut des Sciences de la Nature de l'Université de Nantes (1981).

[3] J. Nikodic, Dynamique sédimentaire dans la partie occidentale de la baie du mont-saint-michel, Ph.D. thesis, Université de Nantes (1981).

[4] SOGREAH, Amélioration de la mytiliculture dans la baie de l'aiguillon, Tech. rep., LCHF (1986).

[5] F. Cayocca, P. Bassoulet, P. Le Hir, H. Jestin, P. Cann, Sedimentary processes in a shellfish farming environment, mont saint-michel bay, france, in: INTERCOH, Sediment and ecohydraulics, 2005, pp. 431446.

[6] SeaMER, Etude d'impact de la restructuration conchylicole en baie du mont saint-michel, Tech. Rep. Etude courantologique et sédimentologique, Rapport SRC Bretagne Nord (2000).

[7] C. Stevens, D. Plew, N. Hartstein, D. Fredriksson, The physics of openwater shellfish aquaculture, Aquacultural Engineering 38 (2008) 145160.

[8] K. Guizien, Etude du champ de vitesses sous une et plusieurs plaques soumises à la houle et immergées près du fond, Master's thesis, Université de Nantes (1996).

[9] Y. Kervella, G. Germain, B. Gaurier, J. Facq, F. Cayocca, P. Lesueur, Experimental study of the near-field impact of an oyster table on the flow, European Journal of Mechanics - B/Fluids 29 (1) (2010) 32-42.

[10] Y. Kervella, G. Germain, B. Gaurier, J. Facq, F. Cayocca, P. Lesueur, Boundary layer development and shear stresses measurements around oysters tables, in: AMT'09, Vol. 5a, AMT'09, 2009, pp. 358-368.

[11] Y. Kervella, Impact des installations ostréicoles sur l'hydrodynamique et la dynamique sédimentaire, Ph.D. thesis, Université de Caen (2010).

[12] D. Plew, C. Stevens, R. Spigel, N. Hartstein, Hydrodynamic implications of large offshore mussel farms, Journal of Oceanic Engineering 30 (1) (2005) 95-108. 
[13] S. Delaux, C. Stevens, S. Popinet, High-resolution computational fluid dynamics modelling of suspended shellfish structures, Environmental Fluid Mechanics DOI = 10.1007/s10652-010-9183-y (2010) 1-21.

[14] H. Darcy, Les fontaines publiques de la ville de Dijon, Dalmont, Paris, 1856.

[15] P. Forchheimer, Wasserbewegung durch boden, Zeitschrift des Vereines Deutscher Ingenieure 45 (1901) 1782-1788.

[16] A. Erriguible, P. Bernada, F. Couture, M. Roques, Simulation of convective drying of a porous medium with boundary conditions provided by cfd, Chemical Engineering Research and Design 84 (A2) (2006) 113-123.

[17] D. Yang, Y. Yang, V. Costa, Numerical simulation of non-darcian flow through a porous medium, Particuology 7 (2009) 193-198.

[18] F. Menter, M. Kuntz, R. Langtry, Ten years of industrial experience with the sst turbulence model, Turbulence, Heat and Mass Transfer 4 (2003) 625-632.

[19] FLUENT 6 User's guide, Volume 1 - 5, fluent europe ltd Edition (Dec. 2001).

[20] P. Le Hir, P. Cann, B. Waeles, H. Jestin, P. Bassoulet, Erodibility of natural sediments: experiments on sand/mud mixtures from laboratory and field erosion tests, Sediment and Ecohydraulics 11 (2005) 137-153. 